\title{
Discussion Paper: The Canberra Meeting: An initiative for building research capacity in health professions education
}

\author{
J. Foo ${ }^{1}$, A. Atherley ${ }^{2,3}$ J. Ash ${ }^{4}$ \& W. Hu ${ }^{3}$
}

\begin{abstract}
Introduction: There are few dedicated health professions education research centres in Australia and New Zealand. As a result, researchers, especially novices, can often feel isolated. In this discussion paper, we introduce The Canberra Meeting - an initiative for building research capacity in health professions education by developing a community of practice through an annual meeting. In this meeting, novice researchers present on significant problems or questions arising from their research, known as a dilemma presentation, and facilitate discussion with an audience of peer PhD students, earlycareer researchers and senior researchers. The meeting aims to provide an opportunity to expand professional networks, exchange ideas and build knowledge.
\end{abstract}

Innovation: A half-day pilot meeting was held in Canberra prior to the 2019 ANZAHPE conference. The meeting was designed for, and planned by, novice researchers. There were 37 attendees, including 13 who self-identified as novice researchers. Three halfhour dilemma sessions were held, comprised of 10 minutes of presentation time followed by 20 minutes of discussion.

Evaluation and outcomes: Feedback on the pilot was sought through prompted group discussions. The following guiding principles were developed, including that the initiative should be 1) inclusive to all health professions and seek to reach isolated researchers; 2) accessible, by providing equal opportunity of access; 3) constructive, such that participants feel safe to present and engage in discussions; and 4) sustainable, such that the community of practice continues despite changes in individual membership.

What's next: Planning is currently underway for a meeting prior to the next ANZAHPE conference. The event will be publicly advertised.

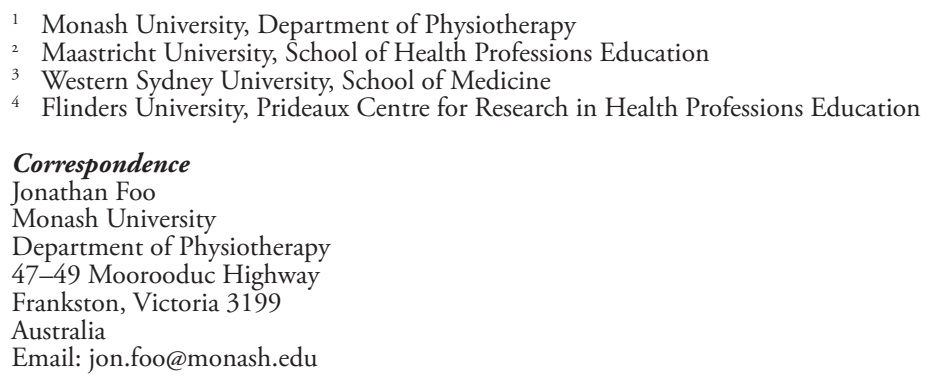


Keywords: community of practice; researcher development; capacity building; health professions education research

\section{Introduction}

Feelings of isolation among $\mathrm{PhD}$ (doctoral) students are a major factor contributing to high-attrition rates from such programs (Ali \& Kohun, 2006; Lovitts \& Nelson, 2000) and may also affect productivity, job satisfaction and career mobility (Belkhir et al., 2019). In a UK survey, $64 \%$ of $\mathrm{PhD}$ students reported feeling isolated (Shaw, 2014). Isolation is likely to affect health professions education (HPE) PhD students in the Australia and New Zealand region given the small number of HPE researchers at any one institution and the tendency for social science researchers to work individually (McAlpine \& Norton, 2006). HPE research leaders and students contacted across Australian and New Zealand universities collectively agreed there was a need to address isolation and build research capacity. Drawing on our perspectives as $\mathrm{PhD}$ students and senior researchers, we report an initiative for addressing this need.

Belkhir et al. (2019) define academic isolation as "an involuntary perceived separation from the academic field to which one aspires to belong, associated with a perceived lack of agency in terms of one's engagement with the field" (p. 262). They propose four dimensions to academic isolation. The first dimension is geographic isolationthe perception of being physically distant from the centres or established scholars in the field. Such PhD students feel that isolation diminishes their ability to identify current research standards. Cultural isolation is the second dimension-when the $\mathrm{PhD}$ student has not acculturated to the norms, values and shared codes of the existing members, resulting in feelings of inadequacy and hesitancy to engage in activities. This is particularly relevant to HPE research that is interdisciplinary and does not "fit" within one field of study. The third dimension is relational isolation - the lack of familiarity or acquaintance with members of the field, which leads to feeling alienated in academic gatherings, such as conferences, and difficulty in developing professional relationships. The final dimension, technical isolation, refers to a perceived lack of fieldspecific scholarly skills, such as command of dominant theories, concepts and methods. Technical isolation may arise from a lack of available mentors at a researcher's institution. Working with others in a systematic, organised way could be key to reducing isolation and has synergies with the theory that learning how to do research takes place through social relationships with other researchers rather than through the simple acquisition of knowledge (Wenger, 2010).

Thus, curating communities of practice $(\mathrm{CoP})$ may reduce isolation and support researcher capacity building (Lahenius, 2012). CoPs are groups of people who share a concern about, and passion for, something they do and seek to learn how to do it better through regular interaction. They facilitate learning through social interaction, knowledge-sharing, knowledge-creation and identity-building (Li et al., 2009). CoPs also provide a fertile ground for developing networks of collaborators, which are associated with research success. Mentoring novices within such collaborative networks also favours career development (Bozeman \& Corley, 2004). Related to this paper is the 
successful European HPE research CoP_the "Rogano" meeting. Rogano inspired the initiative we report in this discussion paper.

Rogano has been held annually since 2011 to coincide with the conference of the Association for Medical Education in Europe (AMEE). The meeting was conceived from a desire to build international relationships with other universities and became an international collaboration between a number of large HPE research groups in Europe, North America, United Kingdom and one Australian research centre. It aims to help novice researchers expand their networks, exchange and advance ideas on individual research dilemmas, provide insights to inform one's own and others' research and, more generally, build knowledge about doing HPE research (https://www.roganomeeting. com). At Rogano, PhD students present significant problems or questions arising from their research (termed a dilemma), facilitating interactive discussions with an audience of peer PhD students, early-career researchers and invited senior researchers.

We believed that developing a CoP in the Australia and New Zealand region, similar to Rogano, would assist in reducing isolation and building future researcher capacity. However, it was necessary to consider contextual differences between the two settings, such as the dispersed nature of $\mathrm{HPE}$ research across universities with few research centres in Australia and New Zealand, compared to Europe or North America, and the lack of an established HPE early-career researcher network. In response, we developed and implemented a half-day pilot meeting to showcase the Rogano model through novice researcher (dilemma) presentations and explored how such an initiative could be best designed to fit local needs.

\section{Innovation}

To develop this CoP, a pilot was designed and implemented by PhD students (JF and AA) under the guidance of senior researchers (JA and WH), with advice from established HPE researchers and mentors. The meeting was scheduled the day before the Australia and New Zealand Association for Health Professional Educators (ANZAHPE) 2019 conference in Canberra. Thus, using the namesake of the pilot location, this meeting has become known as "The Canberra Meeting". Not knowing the likely level of interest, the team invited persons of all experience levels-novice, intermediate and senior-through an open expression of interest invitation distributed to HPE leaders in Australia and New Zealand. All those who submitted an expression of interest were invited to attend. This process yielded 37 participants (13 of whom self-identified as novice researchers). The venue for the half-day pilot was provided by the University of Canberra and co-located with the annual Medical Deans Australia and New Zealand educational leaders meeting to facilitate participation by senior researchers. Novice participants were invited to submit an abstract for a dilemma presentation, and from those submitted, three were selected to showcase the Rogano-style dilemma presentation. This was a new experience for dilemma presenters, however the facilitators (JF and AA) were novice researchers with experience presenting and participating at the European Rogano in 2018. 
Dilemma presentations were central to this pilot initiative. These presentations involved $\mathrm{PhD}$ students presenting problems or questions arising from their research (10 minutes), followed by discussion with the audience (20 minutes). Unlike conference presentations in which presenters often feel the need to portray an air of expertise on their topic, dilemma presentations provide an opportunity for students to say "I don't know" in a safe, constructive environment and overcome technical isolation. Novice researchers in the audience were invited to comment first, thus stimulating peer-led knowledge sharing and knowledge creation (see Figure 1 for the full program). This also avoided discussion being dominated by more senior researchers and attendees. Ensuring that novice researchers were given the first opportunity to contribute to the discussion was closely adhered to, addressing the experience of cultural isolation and acknowledging their identity as active members of a CoP. An audience member volunteered to take notes for each presenter. Lastly, a group dinner was held to further social interaction, build community and address the issue of relational isolation. We hoped the confidence and conversations developed during an inclusive "pre-meeting" would carry over into the ANZAHPE conference.

\section{Figure 1}

Program for the Pilot Workshop on Building Research Capacity in HPE in Australia and New Zealand, 2019

\begin{tabular}{|ll|}
\hline 1:00-1:30 PM & Registration + tea/coffee \\
1:30-2:00 PM & Welcome + Panel presentation on the Rogano concept \\
2:00-2:30 PM & Dilemma session 1 \\
2:30-3:00 PM & Dilemma session 2 \\
3:00-3:15 PM & Refreshment break \\
3:15-3:45 PM & Dilemma session 3 \\
3:45-4:15 PM & Plenary with Renee Stalmeijer \\
4:15-5:00 PM & Workshop: The future of our Rogano concept \\
5:00-5:15 PM & Close (move to ANZAHPE conference reception) \\
\hline
\end{tabular}

\section{Evaluation and outcomes}

Feedback on the pilot presentations was sought in the final workshop activity, through guided group discussions. The aim was to collectively evaluate and further develop the initiative. Overall, all attendees felt they had benefitted from the experience and provided constructive suggestions for the next iteration.

This in-person feedback was in the presence of the organisers, so it is possible that participants' responses could be biased towards more positive comments. While informal, this feedback will allow the authors to mould future iterations of the meeting. More in-depth and rigorous evaluation will be implemented for future meetings. By nature of the exploratory pilot recruitment and design process, we may not have reached significant numbers of isolated $\mathrm{PhD}$ students who may not be identified as HPE researchers (e.g., those working in interdisciplinary fields, who did not hear 
about the event), lack opportunity (e.g., no organisational support to attend) or lack confidence (e.g., lack of self-efficacy to apply).

Through iterative debriefing discussions, based on participant feedback and our observations, the authors articulated the following guiding principles for the initiativethat the initiative should be inclusive, accessible, constructive and sustainable. Each of these is outlined below.

\section{Inclusive}

Researchers from all health professions should be invited to participate in the planning and actualising of the event. This should include researchers of all experience levels, with an emphasis on novice researchers. Specific effort should be made to reach isolated researchers who are unsupported by a dedicated education unit. Many felt that despite the presence of well-known HPE scholarship units in Australia and New Zealand, many early career researchers are still relatively isolated, compared to colleagues in North America and Europe.

\section{Accessible}

Equal opportunity of access to all is to be emphasised, such that novice researchers, in particular, are not disadvantaged by financial, social or professional factors. This means that costs to attendees should be kept to a minimum, with support from institution leaders likely to be key. While face-to-face meetings are invaluable for addressing many forms of isolation, consideration may also be given to online and virtual communities that may at least address technical and geographic isolation.

\section{Constructive}

Presenters should feel safe and comfortable to share their dilemmas, no matter what they are, and novice researchers should be enabled to participate fully in planning and discussion during the event. Discussions should be constructive, focused on the dilemma at hand, and not used as a platform for pushing personal agendas. Processes for handling significant ethical dilemmas and supporting researchers who raise them should be developed with the assistance of an expert panel.

\section{Sustainable}

A sustainable operation structure is imperative, allowing the event and community of practice to continue regardless of changes in the people contributing, particularly due to the potential for handing over to new event leaders each year. A sustainable structure will be facilitated through an ongoing commitment by several senior researchers, with rolling engagement of new novice researchers. The pilot was supported by in-kind contributions from universities and financial contributions from Medical Deans, so that no fees were charged. Ongoing financial feasibility of this initiative is essential. We hope the costs of the event are supported by contributions from field leaders, employers and sponsors. 
BUILDING CAPACITY IN HPE RESEARCH

\section{What next?}

Based on feedback from the pilot attendees, as well as interest from the ANZAHPE community, the Australia and New Zealand version of the "Rogano" concept will continue as a way to build capacity in HPE research. Similar to ANZAHPE's conference planning committees, at each meeting, a new local organising committee will be formed. An overarching advisory board has been established to provide advice and longer-term direction for the initiative. Future questions to consider include the specific roles of the advisory board, the ongoing internal structure (how the initiative functions) and external structure (how the initiative engages with ANZAHPE and other bodies) and engagement from researchers outside the binational context, given the growth of HPE activities in the Australasian region.

Currently, work is underway to organise the next event. Those interested in finding out more or being involved in this initiative can contact the corresponding author.

\section{Funding and conflicts of interest statement}

The event described in this paper received funding support from Medical Deans Australia and New Zealand (MDANZ). The University of Canberra and Australian National University provided in-kind support. The authors maintained full intellectual control of the planning, conduct, writing and approval of the event and this publication.

\section{Acknowledgements}

We thank Medical Deans Australia and New Zealand for their financial and logistic support. We would also like to acknowledge The University of Canberra and Australian National University for their material support. Author JF is supported by an Australian Government Research Training Program Scholarship.

\section{References}

Ali, A., \& Kohun, F. (2006). Dealing with isolation feelings in IS doctoral programs. International Journal of Doctoral Studies, 1(1), 21-33. https://doi.org/10.28945/58

Belkhir, M., Brouard, M., Brunk, K. H., Dalmoro, M., Ferreira, M. C., Figueiredo, B., Huff, A. D., Scaraboto, D., Sibai, O., \& Smith, A. N. (2019). Isolation in globalizing academic fields: A collaborative autoethnography of early career researchers. Academy of Management Learning \& Education, 18(2), 261-285. https://doi.org/10.5465/amle.2017.0329

Bozeman, B., \& Corley, E. (2004). Scientists' collaboration strategies: Implications for scientific and technical human capital. Research Policy, 33(4), 599-616. https:// doi.org/10.1016/j.respol.2004.01.008

Lahenius, K. (2012). Communities of practice supporting doctoral studies. The International Journal of Management Education, 10(1), 29-38. https://doi. org/10.1016/j.ijme.2012.02.003 
Li, L. C., Grimshaw, J. M., Nielsen, C., Judd, M., Coyte, P. C., \& Graham, I. D. (2009). Use of communities of practice in business and health care sectors: A systematic review. Implementation Science, 4(1), 27. https://doi.org/10.1186/17485908-4-27

Lovitts, B. E., \& Nelson, C. (2000). The hidden crisis in graduate education: Attrition from Ph.D. programs. Academe, 86(6), 44-50. https://doi. org/10.2307/40251951

McAlpine, L., \& Norton, J. (2006). Reframing our approach to doctoral programs: An integrative framework for action and research. Higher Education Research \& Development, 25(1), 3-17. https://doi.org/10.1080/07294360500453012

Shaw, C. (2014, May 8). Overworked and isolated: Work pressure fuels mental illness in academia. The Guardian. https://www.theguardian.com/higher-educationnetwork/blog/2014/may/08/work-pressure-fuels-academic-mental-illnessguardian-study-health

Wenger, E. (2010). Communities of practice and social learning systems: The career of a concept. In C. Blackmore (Ed.), Social learning systems and communities of practice (pp. 179-198). Springer. https://doi.org/10.1007/978-1-84996-133-2_11 